\section{Case Reports in Ophthalmology}

Case Rep Ophthalmol 2017;8:21-25

This article is licensed under the Creative Commons Attribution-NonCommercial 4.0 International License (CC BY-NC) (http://www.karger.com/Services/OpenAccessLicense).

Usage and distribution for commercial purposes requires written permission.

\title{
Docetaxel Retinopathy: A Case Report
}

\author{
Sylvia Nghiem-Buffet ${ }^{a, b}$ Salomon Yves Cohen ${ }^{b}$ \\ Audrey Giocanti-Auregan ${ }^{a}$ \\ ${ }^{a}$ Centre d'Imagerie et de Laser, Paris, France; ${ }^{b}$ Ophthalmology Department, Vision and \\ Handicaps, Avicenne Hospital, Bobigny, France
}

\section{Keywords}

Taxanes · Tamoxifen · Toxic retinopathy · En-face OCT · Macular edema

\begin{abstract}
Background: To report the use of En-face optical coherence tomography (OCT) in a patient treated with docetaxel and tamoxifen for breast cancer for the detection of macular edema (ME) without evidence of leakage on fluorescein angiography (FA). Case Presentation: A 52year-old woman treated for breast cancer presented with bilateral visual loss for 2 months. FA showed no significant leakage while spectral-domain OCT scans of both eyes showed foveolar and parafoveolar cystic spaces in a moderately thickened macula. En-face OCT segmented at the inner retina showed the petaloid arrangement of cystic cavities, comparable to a cystoid ME. Conclusions: The combined use of tamoxifen could have potentiated the toxic effect of docetaxel on the macula. En-face OCT images may reveal a petaloid aspect of the macula due to cysts in the inner retina segmentation, when FA shows no leakage.
\end{abstract}

(C) 2017 The Author(s)

Published by S. Karger AG, Basel

\section{Introduction}

Taxanes (docetaxel and paclitaxel) are widely used as chemotherapy agents. They act as mitotic inhibitors, preventing normal reorganization of the microtubule network within cells. Tamoxifen (Nolvadex; AstraZeneca, London, UK) is an oral nonsteroidal anti-estrogen, 
primarily approved for the treatment of estrogen receptor-positive breast cancer. In the literature, both treatments have been reported in association with macular edema (ME), mainly in patients who received high cumulative doses [1].

This report describes the En-face optical coherence tomography (OCT) assessment of a patient treated with docetaxel (Taxotere; Sanofi, Laval, QC, Canada) and tamoxifen for breast cancer who developed ME without evidence of leakage on fluorescein angiography (FA).

\section{Case Description}

A 52-year-old woman presented with bilateral visual loss for 2 months. She had a significant medical history of breast cancer (adenocarcinoma) 1 year earlier. The patient received 4 chemotherapy cycles based on 5 -fluorouracile (Fluorouracile ${ }^{\circledR}$ ), epirubicine (Farmorubicine ${ }^{\circledR}$ ), and cyclophosphamide (Endoxan ${ }^{\circledR}$ ) and 4 treatment cycles based on docetaxel (Taxotere $^{\circledR}$ ) and trastuzumab (Herceptine ${ }^{\circledR}$ ). She had also undergone breast removal and was treated with radiotherapy. A tamoxifen therapy was initiated 2 months before her vision loss (20 mg/day for 2 months, i.e. a cumulative dose of $1.2 \mathrm{mg}$ ).

At presentation, visual acuity was 20/40 OU. Intraocular pressure was normal. Anterior segment examination findings were unremarkable. Dilated fundus examination revealed no evidence of vitritis. Posterior segment examination revealed a decrease in foveal reflex in both eyes (Fig. 1a, b). FA showed normal filling of the choroidal and retinal vessels and an unremarkable parafoveal capillary network. There was no significant leakage on the late phases of the angiograms (Fig. 1c, d). Spectral-domain (SD)-OCT scans (Cirrus 5000; Zeiss, Oberkochen, Germany) of both eyes showed foveolar and parafoveolar cystic spaces in a moderately thickened macula (Fig. 1e, f). The ellipsoid zone was interrupted in the foveal center. En-face OCT segmented at the inner retina showed the petaloid arrangement of cystic cavities, comparable to a cystoid macular edema (CME) (Fig. 1g-j).

\section{Discussion}

Findings from the examination were consistent with a CME in both eyes without any evidence of fluorescein leakage. In this case, a role of tamoxifen in maculopathy development was suggested. Cystoid maculopathy due to tamoxifen has previously been described, and the clinical presentation depends on the cumulative dose: after the use of high doses of tamoxifen (100 g or more), a ME without leakage on FA has been found associated with microcrystalline deposits [2-4]. Pseudocystic foveal cavitations similar in appearance to macular telangiectasia type 2 on OCT [5, 6] have been associated with moderate cumulative doses of tamoxifen (18.25-58.4 g), and in patients treated with very low cumulative doses of tamoxifen (4.2-9.6 g), foveal cysts and/or macular thinning [7] have been described.

In our case, no crystalline deposits or outer retinal cavitation were observed. However, the small foveal intraretinal cysts on SD-OCT without leakage on FA could be compatible with tamoxifen retinopathy, but the cumulative dose of $1.2 \mathrm{~g}$ of tamoxifen was significantly lower than the toxic dose previously described in the literature. Therefore, we could assume that our patient did not develop tamoxifen maculopathy.

On the other hand, 3 cases [8] of CME without fluorescein leakage secondary to docetaxel administration have been reported. In 2 out of the 3 cases, the toxicity of docetaxel has been associated either with retinopathy pigmentosa [9] or with fluid retention syndrome 
[10]. In our case, the combined use of tamoxifen could have potentiated the toxic effect of docetaxel on the macula. This is, to the best of our knowledge, the first case of maculopathy secondary to docetaxel suspected to be potentiated by tamoxifen that is well documented by SD-OCT and for which En-face OCT images showed a petaloid aspect of the macula due to cysts in the inner retina segmentation.

The pathophysiology of CME without angiographic leakage is unclear. Toxicity to Müller glial cells (MGC) with subsequent intracellular fluid accumulation [11] has been suggested, as well as retinal pigment epithelium dysfunction [12]. More recently, electroretinography [13] has shown alterations compatible with a decrease in MGC function, in a case of ME with fluorescein leakage under paclitaxel, another member of the taxane family. In our case, the toxicity of docetaxel to MGC could have affected photoreceptors and led to their alteration and ellipsoid zone disruption.

\section{Acknowledgement}

We received financial support by CIL-ASSOC and AVOPH (Associations for Vision and Research in Ophthalmology).

\section{Statement of Ethics}

The patient gave her consent for the publication of her data (individual details and images).

\section{Disclosure Statement}

Dr. Sylvia Nghiem-Buffet and Dr. Audrey Giocanti-Aurégan have received personal fees from Novartis, Bayer, and Allergan outside the scope of the submitted work. Dr. Audrey Giocanti-Auregan is also a consultant for Alimera outside the scope of the submitted work. Prof. Salomon Y. Cohen has received personal fees from Novartis, Bayer, Allergan, Alcon, and Thea outside the scope of the submitted work.

\section{Author Contributions}

A.G.-A. has collected data and has been involved in drafting the manuscript and revising it critically for important intellectual content.

S.N.-B. was responsible for the conception of the case report and has revised it critically for important intellectual content.

S.Y.C. helped drafting the manuscript and gave his final approval for this version to be published. 
Nghiem-Buffet et al.: Docetaxel Retinopathy: A Case Report

\section{References}

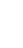

Makri OE, Georgalas I, Georgakopoulos CD: Drug-induced macular edema. Drugs 2013;73:789-802.

Kaiser-Kupfer MI, Kupfer C, Rodrigues MM: Tamoxifen retinopathy. A clinicopathologic report. Ophthalmology 1981;88:89-93.

-3 Griffiths MF: Tamoxifen retinopathy at low dosage. Am J Ophthalmol 1987;104:185-186.

-4 Bourla DH, Sarraf D, Schwartz SD: Peripheral retinopathy and maculopathy in high-dose tamoxifen therapy. Am J Ophthalmol 2007;144:126-128.

5 Gualino V, Cohen SY, Delyfer M-N, Sahel J-A, Gaudric A: Optical coherence tomography findings in tamoxifen retinopathy. Am J Ophthalmol 2005;140:757-758.

-6 Doshi RR, Fortun JA, Kim BT, Dubovy SR, Rosenfeld PJ: Pseudocystic foveal cavitation in tamoxifen retinopathy. Am J Ophthalmol 2014;157:1291-1298.e3.

-7 Chung H, Kim D, Ahn S-H, Kim J-G, Lee JY, Lim JY, Yoon YH: Early detection of tamoxifen-induced maculopathy in patients with low cumulative doses of tamoxifen. Ophthalmic Surg Lasers Imaging 2010, DOI: 10.3928/15428877-20100215-06.

-8 Teitelbaum BA, Tresley DJ: Cystic maculopathy with normal capillary permeability secondary to docetaxel. Optom Vis Sci 2003;80:277-279.

-9 Enzsoly A, Kammerer K, Nemeth J, Schneider M: Bilateral cystoid macular edema following docetaxel chemotherapy in a patient with retinitis pigmentosa: a case report. BMC Ophthalmol 2015;15:32.

10 Telander DG, Sarraf D: Cystoid macular edema with docetaxel chemotherapy and the fluid retention syndrome. Semin Ophthalmol 2007;22:151-153.

-11 Joshi MM, Garretson BR: Paclitaxel maculopathy. Arch Ophthalmol 2007;125:709-710.

12 Kuznetcova TI, Cech P, Herbort CP: The mystery of angiographically silent macular oedema due to taxanes. Int Ophthalmol 2012;32:299-304.

13 Nakao S, Ikeda Y, Emi Y, Ishibashi T: Possibility of Müller cell dysfunction as the pathogenesis of paclitaxel maculopathy. Ophthalmic Surg Lasers Imaging Retina 2016;47:81-84. 


\section{Case Reports in Ophthalmology}

\begin{tabular}{l|l}
\hline Case Rep Ophthalmol 2017;8:21-25 \\
\hline DOI: 10.1159/000455088 & $\begin{array}{l}\text { @ 2017 The Author(s). Published by S. Karger AG, Basel } \\
\text { www.karger.com/cop }\end{array}$ \\
\hline
\end{tabular}

Nghiem-Buffet et al.: Docetaxel Retinopathy: A Case Report
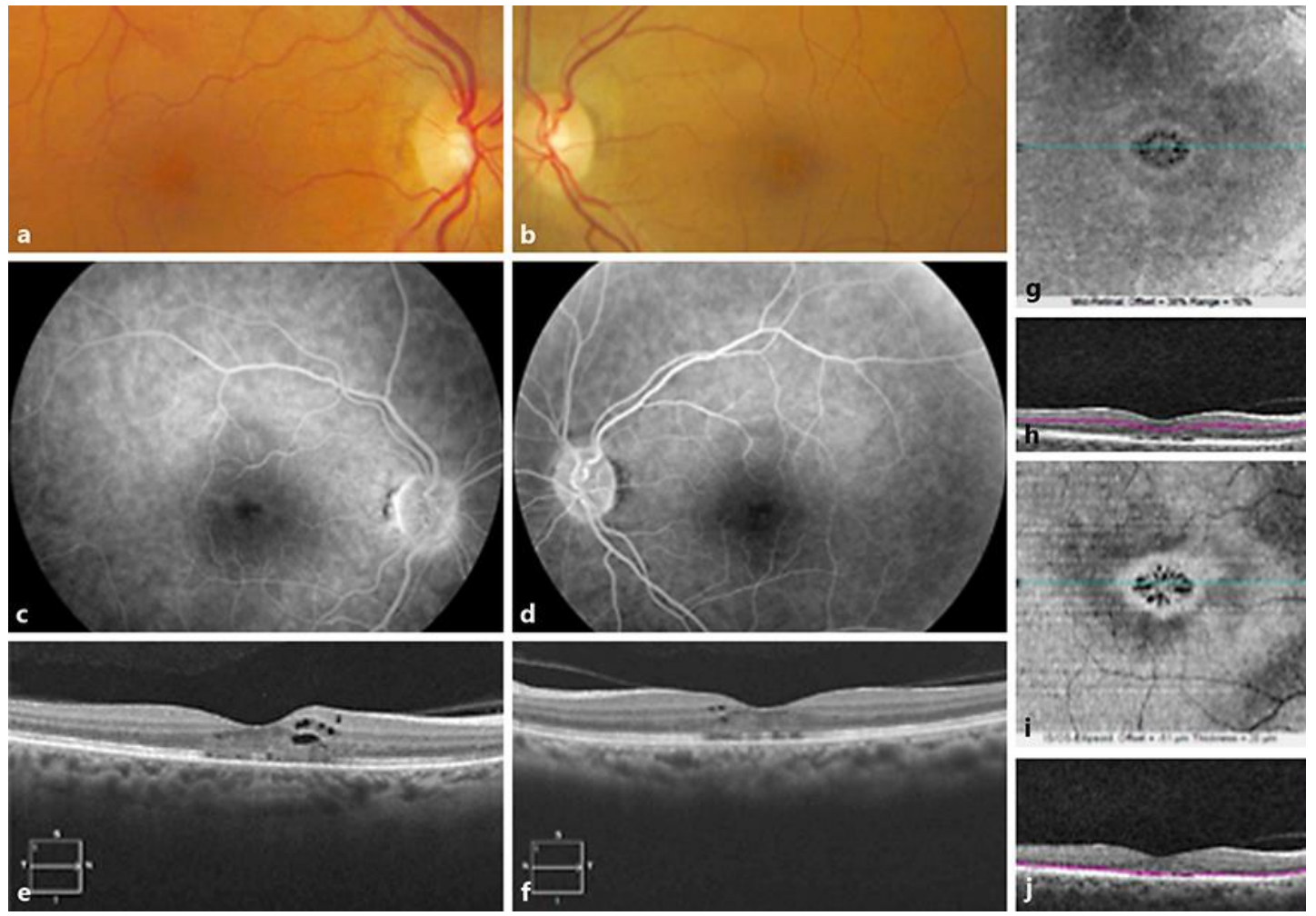

Fig. 1. Bilateral cystoid macular edema in a 52-year-old woman treated with tamoxifen and docetaxel. Fundus color photograph of the right eye (a) and the left eye (b): stellate appearance of the macula. Late phase of the fluorescein angiogram in the right eye (c) and the left eye (d) shows no dye pooling in cystoid spaces. SD-OCT horizontal B-scans of the right (e) and left eye (f) showing intraretinal cysts and fragmentation of the ellipsoid zone. Right eye En-face OCT (g) and its segmentation (h) in the right inner retina showing the petaloid aspect of cysts in the macula. Right eye En-face OCT (i) and location of its segmentation (j) in the right outer retina showing the petaloid aspect of the outer retina. 